\title{
Experiential Learning for First Year Engineering through Outreach with a Local Community Hospital
}

\author{
Abbey Desjarlais ${ }^{1}$ and Robert V. Fleisig, PhD, PEng ${ }^{2}$ \\ ${ }^{1}$ Faculty of Engineering, ${ }^{2}$ Walter G. Booth School of Engineering Practice, ${ }^{1,2}$ McMaster University \\ desjaram@mcmaster.ca, robert@mcmaster.ca
}

\begin{abstract}
The lecture is the staple of university learning. It can be effective in the teaching of fundamental engineering subjects such as calculus and physics. However, it offers little in bringing students to understand the role of the engineering profession and its practice. With limited budgets, time and resources, and large first year classes, creating a poignant learning experience for our students is immensely challenging. Yet the university classroom offers an unparalleled opportunity given its diverse pool of talent, skill, and ambition. With guidance our students have the ability to not only meet our high academic expectations but also make a real difference for people in their local communities. At McMaster University, our entire first year engineering cohort is contributing to their local community through interactions with medical professionals and their clients. With an increased emphasis on design, experiential learning, and community outreach we at McMaster University have developed a unique first year course that involves the design of rehabilitation devices in collaboration with occupational therapists, researchers, industry professionals, and local volunteers. The project provides students with a rich and real-world practice experience as well as benefiting those clients with unique problems. This paper describes the successful collaboration between the Hand Therapy Clinic at Hamilton General Hospital and the Engineering 1 programme at McMaster University. The occupational therapists at the clinic presented $800+$ first year engineering students with a challenge: design a dynamic elbow orthosis for the unique problems faced by two of their clients. Volunteers from the local community of occupational therapists, industry professionals, and biomedical researchers worked with the students to help them design, build, and test their designs. The paper highlights the challenges of teaching the large class using experiential learning and outlines the approaches for challenging students with unique problems that demand creativity.
\end{abstract}

Keywords: practice-based problems, engineering design, experiential learning, freshmen engineering, design thinking

\section{INTRODUCTION}

It is generally accepted that the staple of engineering education is engineering fundamentals. These are inherently centred on the students learning and applying scientifically validated knowledge. Usually this knowledge is considered fundamental to the researchers who instruct these courses, and the content is heavy and difficult. Students mostly learn through lectures and apply that knowledge through academically wrought assignments evaluated by teaching assistants, with a final comprehensive evaluation in the form of a written final examination for each course. A myriad of engineering fundamentals in each discipline is taught in this manner. The emphasis is on demonstrating an understanding of the underlying concepts and mathematics in these areas.

These same students will enter a workplace in which fundamental engineering knowledge will, at most, occupy a small portion of their time, effort, and intellectual energy. The material, while fundamental, is assumed to be well understood by the employee.

Yet many problems in practice do not easily resemble the definitions of the problems resolved and demonstrated through scientifically validated workings of engineering researchers. Schön [1] noted that the challenges of the professions often transcend the boundaries of the knowledge undergraduates are taught. The design of an automobile is not simply about the optimization of a design to reduce weight or the application of thermodynamics to design an impressive internal combustion engine. To create and deploy the successful design requires consideration of human needs, wants, and desires, both those of the customer and those of the stakeholders in the business. While it is necessary for these problems to leverage existing scientifically validated knowledge, they must also resolve the particular, rather than general, issues of practice which normally occur in the process of working with other 
human beings. These problems were properly described by Schön [1] and noted to have the following characteristics [2]:

1. problem understanding evolves with attempts to solve the problem;

2. problems often lack necessary data, knowledge, and information;

3. problems have no right answer;

4. problems are unique;

5. problems involve uncertainty; and

6. problems contain contradictions of values and requirements.

This paper describes an introductory course whose focus is on teaching students the abilities needed to approach complex design problems with the above characteristics. The approach taken is one of experiential learning based on Kolb's experiential learning model [3]. The paper describes the course model, execution and results of student work.

\section{EXPERIENTIAL LEARNING}

The course ENGINEER 1P03 (Engineering Profession and Practice) is an introduction to the challenging, realworld practice of the engineering profession for the entire class of 800 to 1000 first year undergraduate engineering students at McMaster University. To engage the students in the delivery and learning of design problems, an experiential learning approach was adapted.

Experiential learning is based on Kolb's experiential learning model [3], which involves:

1. a Concrete Experience,

2. followed by Reflective Observation,

3. followed by Abstract Conceptualization; and

4. Active Experimentation of the conceptualization.

Kolb states that in order to gain genuine knowledge from an experience; certain abilities are required [3]:

- The learner must be willing to be actively involved in the experience;

- The learner must be able to reflect on the experience;

- The learner must possess and use analytical skills to conceptualize the experience; and

- The learner must possess decision-making and problem solving skills in order to use the new ideas gained from the experience.

To create the experiential learning in this course, the course was centred on a real-world project with a real client, an immediate problem, and real interactions with both the physical (functional design) space and stakeholders.

\section{DESIGN OF A DYNAMIC ELBOW ORTHOSIS}

Two Occupational Therapists (both registered in Ontario) from the Hand Therapy Clinic at Hamilton General Hospital happily volunteered to be the clients for the course project. They offered a myriad of potential design problems. After some discussion, two of their clients (hereafter referred to as Mr. B and Mr. F [4]) were selected as the subject of the design project. Both clients were in need of better elbow orthoses since neither clinicbuilt splints nor commercial products met the needs of the clients. An elbow orthosis is a device used for various types of therapy. Its principal function is to hold the elbow at a fixed angle even in the presence of resistance from the body. An example is shown in Figure 1.

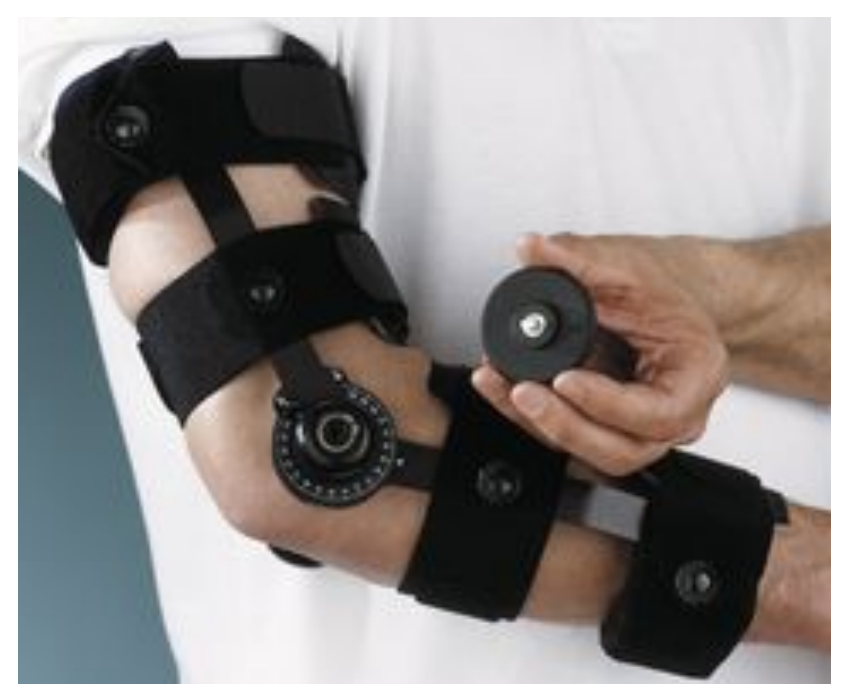

Figure 1: A commercial elbow orthosis.

The first user (or clinic's client), Mr. B, was a 23-yearold single male who was involved in a serious motorcycle accident resulting in a compound fracture, dislocation of the right elbow/shoulder and degloving of the right wrist with tendon/nerve lacerations and a brachial plexus injury. The nerve was grafted six months after the injury. The finger and wrist muscles worked but Mr. B had very little working muscle at the shoulder and none at the elbow. He wanted to be able to lock the elbow splint at various positions to allow him use his hand. He would have liked to be able to vary the forearm rotation. He needed the splint to be very light as his shoulder was already subluxed from the weight of his arm. He would have liked to be able to work on active assistive range of motion (AAROM) exercises with the brace on. He was awaiting trial on a drug charge and would have liked a splint that would be permitted in general population if incarcerated. 
The second user (and the clinic's client), Mr. F, was a 29-year-old single male who sustained second and third degree burns to $20 \%$ body surface area (BSA) including face, arms, and upper back. He also sustained inhalation injuries. An orthopedic surgeon released heterotopic ossification of the left elbow. Mr. F had limited hand function bilaterally. He found it very difficult to change the angle mechanism on his existing splint and struggled to fasten Velcro straps. Poor skin quality because of burns/grafts combined with straps caused blisters and put him at risk of infection $\mathrm{He}$ lived with his parents and disliked asking for more help. Stiffness and swelling in his elbow made it difficult to create enough force with the hinge to maintain at end range.

\section{STUDENT EXPERIENCE}

The student experience of a real-world design project began from the moment the student walked into the first lecture and first tutorial. Setting the final goal, making the goal relevant, and motivating the students were the objectives of the initial interaction with the class. The course was supported by an appropriate practice-based project, stakeholder interactions and learning experiences in visualization.

The design of the dynamic elbow orthosis was the primary focus of the course in the fall of 2012. The enrolment peaked at 855 students from all seven departments. McMaster's Faculty of Engineering has a common first year programme for all engineering disciplines. The course runs over a 12 -week period with two 50-minute lectures per week and a one-hour and 50minute tutorial per week. The support staff of 19 includes a part-time coordinator (shared with two other first year courses), three full-time undergraduate teaching assistants, seven 130-hour graduate teaching assistants, and eight part-time undergraduate teaching assistants. The students themselves worked on teams of four or five with a total of approximately 175 teams in the class.

\subsection{Problem Definition}

Creating a meaningful, real-world design experience for more than 800 first year engineering students without access to shop facilities or prototyping resources was a significant challenge. In addition, to make the project meaningful it had to have the attributes of openendedness, where both the outcome and the problem were not easily or initially defined, meaning the students had to discover the problem as the course progressed [5][6]. Furthermore, to make the problem practicable in the course it had to be unique, otherwise students were likely to copy solutions from elsewhere. There exists a conflict in the uncertainty between the understanding of the topic and the value of it, for instance the users' desire to have a device that they would be comfortable using in public, versus the clinic's cost concerns [1].

Ultimately, the selected problems proved to have all these characteristics. Prototyping functional solutions was considered a requirement. This would help the students visualize and test complex ideas while adding to the tangibility of the project work, making it more real and meaningful to the students. Students were introduced to the idea of prototyping through examples and demonstrations in lecture, followed by an assignment that required them to visit a hardware store to identify parts and products that could fulfill the functions of a dynamic elbow splint. Students were expected to construct the prototypes on their own outside of the classroom. The clients' constraints were similar to those of the students'. The client required that the designs be something they could build in their own clinic with minimal tools, materials, time, and cost. Photographs of the clinic were collected by the teaching assistants and shared with the students.

\subsection{Process and Organization}

The majority of lectures and tutorials were designed to support student work on the project. Early tutorials were set aside for learning ideation techniques associated with functional design. Students used common design exercises such as the Marshmallow Challenge [6] and design/build exercises using fischertechnik ${ }^{\circledR}$ products.

In lectures, the engineering design process was introduced using examples and a previous students' illustration of the process described by Dym and Little [7]. Once the project was introduced, the guest speakers provided opportunities for the students to develop an understanding of the problem, people, business, and technology underlying the given area of investigation.

After setting team charters, students began initial research followed by ideation. As part of the research the class was expected to decompose existing designs into functions, and then visit a hardware store or the like, to find components and parts that could fulfill the functions. Creativity was encouraged.

Ideations were done on paper as sketches in consecutive weeks with TA feedback, both given in person and as written feedback on the submitted work. Shortly thereafter students were asked to construct functional prototypes on their own between tutorials. The initial prototypes were used by the students in presentations to the client to elicit feedback. Each team had an opportunity to talk directly to the client for between five and ten minutes. The client was occasionally represented by volunteers from the local community of practicing Occupational Therapists.

At the end of the course students were expected to present a poster, a working prototype, report, and two- 
page summary of their project. The top projects went to a showcase that was judged by a group of experts where the top projects were celebrated.

\subsection{Stakeholder Interaction}

To add to the discovery aspect of the project and to better engage the students in the project, community stakeholders were invited to make presentations in lecture, critique each team's initial prototype, and evaluate the final presentations and prototypes. Guest lecturers included the client, a former elbow splint user, a biomechanics researcher, an Occupational Therapist/sales person who supports clinics, and the engineering-owner and operator of a medical device company. In all cases, the presentations were directly applicable to the project. Students were encouraged to ask questions that would increase their understanding of the problem and approaches to resolving the problem. The clients organized volunteers from their community of fellow practitioners who spent five to ten minutes with each of the student teams to provide feedback on their prototypes. At the end of the course, a panel of judges was assembled from the community including health science researchers, engineering professors, and clients.

\subsection{Visualization and Functional Design (Creativity)}

To allow the students to be creative, they need the framework from which to see the world and the methods for expressing their complex ideas.

Functional design is based on the notion of abstraction. For example, students were asked to consider the function of a device such as that shown in Figure 1. Then they were asked "what does the hinge do?" The most common answer was that it allowed rotation. Students were then challenged on this: "is rotation allowed without the hinge?" Clearly, it is. Quickly the students reversed their perspective to say the hinge limits motion. Further questioning led to a more refined statement of how the hinge limits motion, to a notion such as "the hinge maintains a planar motion of the arm around a pivot." This led to questioning of the need for a 'second hinge,' given that the elbow can act as a hinge. Given this new understanding of the function of the hinge, students were asked to generate alternatives ideas. This led to novel ideas of how to perform the function of the commercial hinge in the orthosis.

Sheets of 12 inch by 24 inch thermoplastic were made available to the students for purchase as a prototyping material. A video was also created to provide instructions on use of the material.

\subsection{Reward and Motivation}

This unusual and open-ended project challenged many students from the beginning. It was critically important that students be motivated at the start and promised a reward at the end. The idea of a project with a client who had a real-world and immediate need was introduced in the first lecture. Through a simple narrative, it was communicated that the problem was one that could not be found in a textbook but represented the kind of problem that would be the focus of their careers.

The best projects were selected at the end of the term by way of a competition, providing a reward along with the employment of one or two students over the summer to implement some of the best ideas in the clients' clinic.

\subsection{Teaching Assistant Training}

The teaching assistants for the course were a crew of full-time undergraduates and part-time graduate students from the Faculty of Engineering. Their role in the tutorials included facilitating the project, making presentations, and grading student work. The notion of facilitation was new to most of the TAs. As such, all teaching assistants received training on two separate occasions.

In the first training sessions, the TAs participated in an afternoon-long design exercise involving the design of an ankle orthosis for patients with the condition of foot drop common amongst those with multiple sclerosis (MS).

A second training session was organized and led by the Centre for Leadership in Learning at McMaster University. This session emphasized the TAs' roles as facilitators and coaches. Student learning is greatest when they are allowed an element of discovery. The inquirybased training emphasized guiding the students to ask questions and follow-up with their own ideas and answers, rather than directed learning towards a predefined goal.

\section{RESULTS AND DISCUSSION}

The students' response to the course was highly positive. As well, the teaching assistants responded with a very high level of satisfaction with their contribution to the course.

During the course, initial student reactions to the project were mixed. The idea that projects are openended, uncertain, and poorly defined creates anxiety. 


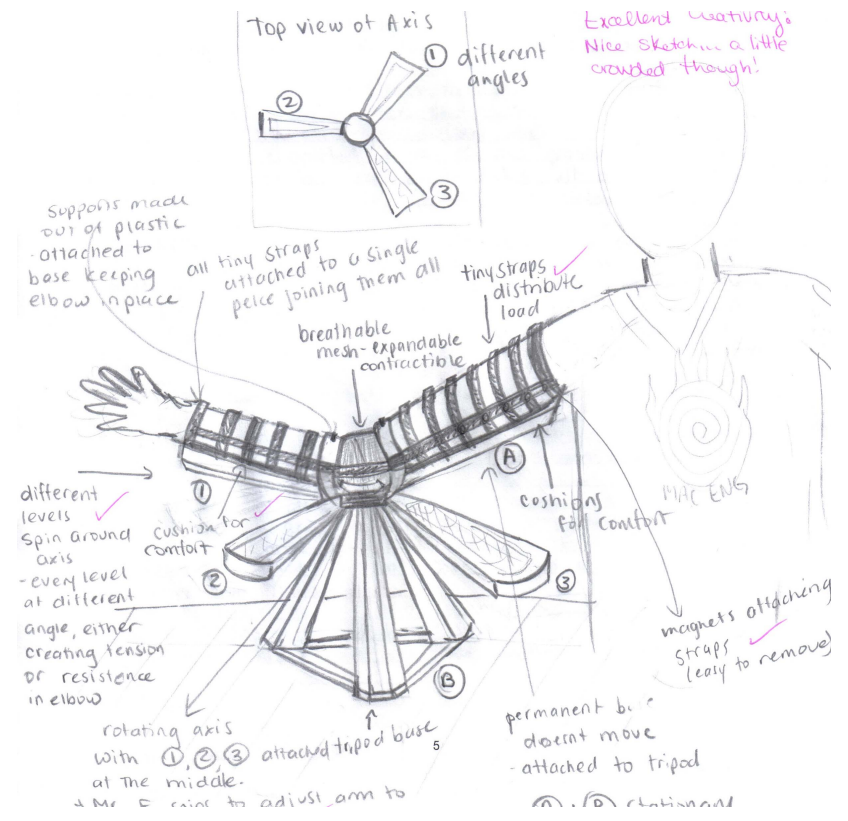

Figure 2: Initial sketch by student team.

Initial sketches done by students on the project demonstrated a strong tendency towards resolving the clients' problem from the point of view of a commercial product-based firm. Many sketches suggested highly complex, although sometimes ingenious, ideas, which after careful scrutiny with the team were determined to be directions that did not make sense for the client. Some teams had difficulty properly defining the problem and instead resorted to working on existing ideas collected from commercial products. A lecture discussion on the design criteria project cleared up most difficulties around this issue.

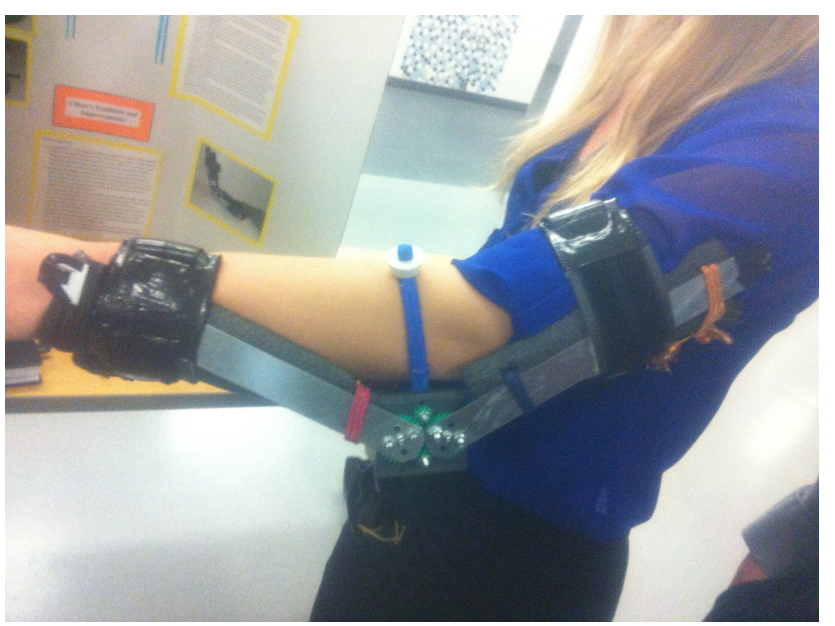

Figure 3. Student wearing prototype elbow orthosis.

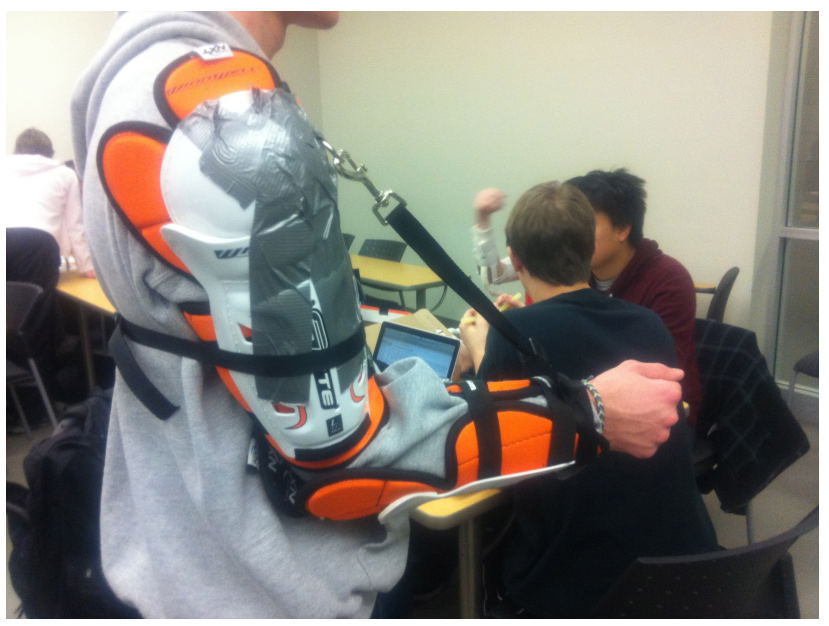

Figure 4. Student wearing prototype elbow orthosis.

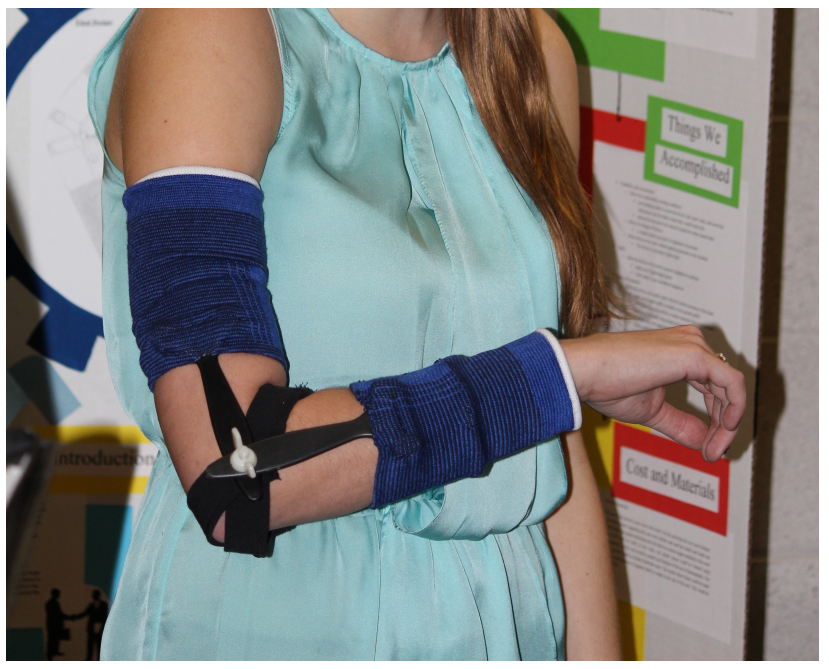

Figure 5: Student wearing prototype elbow orthosis.

At the end of the project, the clients received a 350page compilation of project summaries. Each team submitted a two-page PDF in a predetermined format. The summary included annotated images/photographs of the teams' prototypes and explanations of its function, construction, benefits, and associated costs. The clients found that merely paging through the substantial volume was a valuable exercise as the students had demonstrated a remarkable amount of creativity, particularly in their selection of components and materials. Examples of student prototypes are shown in Figure 3, Figure 4, and Figure 5.

\section{CONCLUSIONS}

The objective of the course was to introduce students to real-world problem solving. Students received a taste 
of the creative process, teamwork, communication, and professionalism. Strong student evaluations suggest students enjoyed the course and found it engaging. Problems still persist with students' perception of the value of the course, and some students resent having to work in a field they are not interested in.

\section{Acknowledgements}

Ms. Tara Packham and Ms. Pam Ball of the Hand Therapy Clinic at Hamilton General Hospital deserve tremendous praise for the empathy and dedication they demonstrate towards their clients. Their time as the client for the course project was given without reservation and with great enthusiasm. It was a pleasure to work with them.

Professor Daryl Caswell [8] of the University of Calgary was a source of great inspiration for the design, development and execution of this course (ENGINEER 1P03: Engineering Profession and Practice) in the fall of 2012. His insights and generosity of time discussing ideas and creativity in design were instrumental to the success of the course.

The course, ENGINEER 1P03: Engineering Profession and Practice, is approved by the McMaster Research Ethics Board for human-participant research subject to annual renewals (MREB Number: 2010 043).

\section{References}

[1] Donald A. Schön, Educating the Reflective Practitioner: Toward a New Design for Teaching and Learning in the Professions, Jossey-Bass, 1987, 376 pp. \{978-1555422202\}

[2] Nigel Cross, "Designerly ways of knowing," Design Studies, vol. 3, no. 4, pp. 221-227, October 1982.

[3] David Kolb, Experiential Learning: experience as the source of learning and development, Englewood Cliffs, NJ: Prentice Hall, 1984, 288 pp. \{ISBN: 978-0132952613\}

[4] Tara Packham, "Why elbow splints?", presentations made on October $12^{\text {th }}, 2013$ to the ENGINEER 1P03 class in TSH 120 at McMaster University.

[5] Clive L. Dym, Alice Agogino, Ozgur Eris, Daniel Frey, Larry Leifer, "Engineering Design Thinking, Teaching, and Learning," Journal of Engineering Education, vol. 94, no. 1, pp. 103-120, 2005.

[6] Clive L. Dym and Patrick Little, Engineering Design: A Project Based Introduction, Wiley, 2008 ( $3^{\text {rd }}$ ed.), 352 pp. $\{978-0470225967\}$

[7] Tom Wujec, “The Marshmallow Challenge," http://marshmallowchallenge.com.

[8] Daryl Caswell, Green Guide No. 7: Creative Problem Solving, The Society for Teaching and Learning in Higher Education, 2006, 44 pp. \{ISBN: 0-9378227-24\} 